\author{
Anna Skolimowska \\ https://orcid.org/oooo-0002-2346-9149 \\ Wydział „Artes Liberales” \\ Uniwersytet Warszawski
}

\title{
Hiszpańskie edycje Hymnów religijnych Jana Dantyszka jako narzędzie autokreacji wydawcy*
}

Edycje hiszpańskie dziełka Dantyszka Hymni aliquot ecclesiastici (Kraków 1548), opublikowane wiele lat po śmierci autora staraniem jego zięcia Diego Graciána de Alderete, w istocie nie są przedrukiem edycji krakowskiej, lecz kompilacją trzech druków: Hymni aliquot ecclesiastici (1548), Dantyszkowego poematu De nostrorum temporum calamitatibus (1530) oraz Genethliacon dla Dantyszka pióra Caspara Ursinusa (1522). Gracián, uzupełniając je przedmową o charakterze panegirycznym oraz znacząco ingerując $w$ tekst poematu Ursinusa $\mathrm{i}$ w teksty wstępne, zaczerpnięte $\mathrm{z}$ pierwotnych edycji, konstruuje z nich pomnik wybitnych dokonań oraz świadectwo nieskazitelnej moralności teścia.

The Spanish editions of Dantiscus' minor work Hymni aliquot ecclesiastici (Cracow, 1548), submitted for publication many years after the author's death by his son-in-law Diego Gracián de Alderete, in fact, are not a reprint of the Cracow edition but a compilation of three prints: Hymni aliquot ecclesiastici (1548), Dantiscus' poem De nostrorum temporum calamitatibus (1530), and the Genethliacon for Dantiscus penned by Caspar Ursinus (1522). Gracián

* Artykuł ten stanowi rozszerzoną polską wersję referatu $A$ Dowry Recovered after Three Decades. Diego Gracián's Spanish Editions of Ioannes Dantiscus' "Hymns” Revisited, w: Acta Conventus Neo-Latini Albasitensis. Proceedings of the Seventeenth International Congress of Neo-Latin Studies (Albacete 2018), ed. F. Schaffenrath et al., Leiden-Boston 2020, s. 550-561. 
uses them to build a monument to his father-in-law's outstanding achievements and a testimony to his impeccable morals, supplementing them with a panegyrical preface and making significant changes to the poem by Ursinus and to introductory texts taken from the original editions.

Słow a klu c z ow e: renesans, Jan Dantyszek, Diego Gracián de Alderete, poezja, religia, autokreacja

Ke yw o rds: Renaissance, Ioannes Dantiscus, Diego Gracián de Alderete, poetry, religion, self-promotion

W 1548 r. w krakowskiej oficynie drukarskiej prowadzonej przez wdowę po Hieronimie Wietorze, staraniem Stanisława Hozjusza, podówczas kanonika warmińskiego, opublikowana została książeczka zawierająca hymny religijne przeznaczone na różne okazje, poczynając od Środy Popielcowej i kolejnych niedziel Wielkiego Postu, poprzez liturgię godzin o Męce Pańskiej, po uroczystości Zmartwychwstania, Wniebowstąpienia i Zesłania Ducha Świętego, a także utwory skierowane do Najświętszej Maryi Panny. Książeczka ukazała się anonimowo, wiadomo jednak, że jej autorem był Jan Dantyszek, dożywający swoich lat na biskupstwie warmińskim. Zmarł on kilka miesięcy po ukazaniu się dziełka ${ }^{1}$.

W pięciostronicowym prologu do hiszpańskiej edycji Hymni aliquot ecclesiastici Dantyszka $(1571,1576)^{2}$ Diego Gracián de Alderete opisuje autora Hymnów (prywatnie własnego teścia) w samych superlatywach. Mówi o nim:

${ }^{1}$ [J. Dantyszek], HYMNI ALIQUOT ECCLESIASTICI, VARIIS versuum generibus, de Quadragesimae Ieiunio, \& sex eius diebus Dominicis, deq(ue) horis Canonicis Christi Passionis tempore. Et de Resurrectione, Ascensione, Spiritussancti missione, Matreq(ue) gloriosissima Maria Virgine, recens aediti, Cracoviae 1548, BO, sygn. XVI.O.696 (dalej: Dantyszek, Hymni 1548).

2 J. Dantyszek, HYMNI ALIQUOT ECCLESIASTICI, VARIIS VERSUUM GENERIBUS, DE Quadragesimae Ieiunio, \& sex eius diebus Dominicis, deque horis canonicis, Christi passionis tempore, \& de resurrectione, Ascensione, Spiritus Sancti missione, matreque gloriosissima Maria virgine, recens aediti, Salamanticae 1571, 1576 (dalej: Dantyszek, Hymni 1571, 1576), egz. 1571: Biblioteca Nacional de España, sygn. R/28169; egz. 1576: Real Biblioteca del Monasterio de San Lorenzo de el Escorial, sygn. 18-VI-30; inne egz. por. A. S. Wilkinson, Iberian Books. Books Published in Spanish or Portuguese or on the Iberian Peninsula before 1601 / Libros ibéricos. Libros publicados en español o portugués o en la Peninsula Ibérica antes de 1601, Leiden-Boston 2010, s. 162. 
vir sane pius iuxta ac doctus, qui multis legationum functus honoribus et poetica lauru coronatus, suae gentis nobilitatem ad eandem laudem accendit, [-- ] tanto officio et pietate erga Deum praeditus fuit, ut olim iuvenis Hierosolyman reliquaque Palaestinae loca religionis ergo peragraverit [--] talis mihi olim adolescenti notus fuit pene cotidiana consuetudine ${ }^{3}$.

Następnie zrównuje cnoty Dantyszka z nadzwyczajnymi zaletami charakteru jego córki, a swojej żony - Juany Dantiski, „quae [--] certe ingenio morumque dexteritate ac reliquis animi dotibus ita semetipsam illi adaequavit, ut sexu tantum, non autem virtute, inferior videretur".

W uszach badacza korespondencji Dantyszka ta gloryfikacja brzmi jednak nieco podejrzanie. Znamy dziewięć listów Graciána do Dantyszka i jeden list Dantyszka do Graciána z lat 1536-15464. W niemal wszystkich tych listach przewija się wątek bezskutecznych starań Graciána o posag dla żony. Wprawdzie Gracián zwraca się zawsze do teścia tonem pełnym szacunku, jednak dla ich niełatwych relacji znamienny jest choćby początek ostatniego listu Graciána, wysłanego w 1546 r., po siedmioletniej przerwie w korespondencji:

Etsi statueram nihil umquam ad te scribere, tamen idoneum ac certum tabellarium oblatum, nempe dominum Stenelaum, non sum passus vacuum meis litteris abire, existimans has saltem ad manus tuas perventuras, quemadmodum mendacia et calumniae ad aures tuas pervenerunt ${ }^{5}$.

Owe „kłamstwa i oszczerstwa” („mendacia et calumniae”) dotyczyły rzekomej interesowności Graciána, choroby francuskiej, na którą miał cierpieć, jego domniemanych relacji seksualnych z matką Juany oraz wyolbrzymianej różnicy wieku między małżonkami. U podstaw fałszywych oskarżeń leżała zdaniem Graciána złośliwość luteranów. Nieodmiennie podkreślał on też w listach do teścia, że motywy jego postępowania były bezinteresowne, a małżeństwo układało się pod

3 Dantyszek, Hymni 1571, 1576, k. A 1 rec.

4 Corpus of Ioannes Dantiscus' Texts \& Correspondence / Korpus Tekstów i Korespondencji Jana Dantyszka, ed. A. Skolimowska, M. Turska, with collaboration of K. Jasińska-Zdun, dantiscus.al.uw.edu.pl (9 I 2020) (dalej: CIDTC), IDL (skrót odnosi się do listów z korespondencji Dantyszka) 1538, IDL 1712, IDL 1656, IDL 1657, IDL 1658, IDL 1770, IDL 1862, IDL 1861, IDL 1982, IDL 2969. Tamże znajdzie czytelnik kompletną bibliografię dotyczącą Dantyszka oraz współczesnych publikacji jego utworów poetyckich i korespondencji.

5 Ibidem, IDL 2969. 
każdym względem znakomicie. Zawsze szczególnie przy tym zaznaczał niepospolite zalety małżonki ${ }^{6}$.

Prawdomówność Graciána w tym zakresie potwierdzają liczne późniejsze źródła. Jednym z nich jest utwór Juana Cristóbala Calvete de Estrella pt. Ad Antonium Gratianum Dantiscum encomium, umieszczony we wstępie do edycji hiszpańskiego przekładu Moraliów Plutarcha autorstwa Diego Graciána z 1571 r. Calvete sławi w tym wierszu cnoty jednego z synów Diego Graciána i Juany Dantiski Antonia, zapowiadając jego rychłą karierę na dworze króla Hiszpanii. Pisze m.in.:

At donis aliis refers parentem

Ioannam genere et pudore claram

6 „Tametsi ego omnino praesagiens futura vaticinatus sum eos actum agere, nam quod in litteris ipsius domini Alphonsi ais me morbo diutissime laborasse eque modo decumbere, commentum est illorum, qui tibi item persuaserunt me etiam cum socru Isabella rem habere, et alia non minus nefaria quam absurda et falsa, quae tu mihi nuper tuis litteris tecte significasti, idest hominum quorundam mendacium, $\grave{\alpha} \theta \varepsilon ́ \omega \nu$ et Lutheranorum, qui nos Hispanos oderunt cane peius et angue, quibus eo nomine potissimum Hispani suspecti sumus, quod lucernam noctu accendimus. Etenim eiusmodi homines apud nostrates (ut scis) non solum mendaces, abiecti et ignobiles, sed et abominabiles et exsecrabiles habentur nec digni hominum communione, sed mari terraque vitandi, in quos nulla poena aut supplicium sit satis officiosum, etsi vivi concrementur, prout fit eis, quotquot depraehenduntur. Quandoquidem ipse ab eo tempore, quo Dantiscam uxorem duxi, neque morbo neque alio quopiam laboravi, sed valui valeoque cum uxore et liberis munere Dei Optimi Maximi, qui mihi hoc et aliis hoc genus beneficiis rependit opus bonum, quod eius contemplatione tantum operatus sum, dum Dantiscam inopem, egenam, desertam ac miserabiliter derelictam, indotatam uxorem duxi matremque mea pecunia adiutam locavi eo tempore, quo illius pudicitia erat periclitatura, huius autem vita infamia laborabat utraque certe vel fame periturae aut quaestum corporis turpiter facturae, ni praeveniens subvenissem idque contempta alibi dote, quam tunc temporis ingentem potui accepisse. Nec me paenitet facti, nec est, cur paeniteat, quotiens enim operamur spirituale aliquid bonum, ut placeamus oculo illi Dei vigili, qui numquam sopitur cuique nuda et aperta sunt omnia, et thesaurus noster indepredabilis et incorruptae retributiones [--] et suavis exspectatio manebunt. Eo maxime, quod ipsi Dantiscae satis magna dos est sua virtus, probitas et non cessuri nisi diis sine crimine mores nudaque simplicitas purpureusque pudor. [--] Haec ad te scribem certum nuntium nactus, ne existimares me tacendo assentiri Lutheranis illis et mendacibus (quos mens intelligit), qui tibi sinistra omnia posthabito Dei timore persuaserunt de nobis, magis ut obsequerentur malitia sua, quam ut nobis incommodarent, qui ut illos contemnimus et abominamur, ita per eos a(!) te quodam modo desperavimus", ibidem, IDL 2969. 
Dantiscam, et Niobe quidem superba

Fecundam magis et beatiorem

Tam multa roseo decore prole ${ }^{7}$.

Opisana tu Juana Dantisca urodziła się w Valladolid w początkach 1527 r. jako córka Jana Dantyszka (1485-1548), humanisty i dyplomaty w służbie króla Zygmunta I i królowej Bony, oraz jego hiszpańskiej kochanki Isabelli Delgady. Polski poseł rzeczywiście - jak podkreślono w cytowanym powyżej utworze, określającym Juanę słowami „genere clara” - czyli „sławna, szlachetna, znamienita rodem” - był szlachcicem, i to zarówno niemieckim, jak i hiszpańskim. Urodził się wprawdzie w rodzinie mieszczańskiej, lecz w 1516 r. w uznaniu wybitnych uzdolnień i zasług został nobilitowany przez cesarza Maksymiliana. Kolejny cesarz, a zarazem król Hiszpanii, Karol V, udostojnił jego herb w roku $1528^{8}$. Wkrótce potem Dantyszek opuścił na zawsze Hiszpanię, podążając z dworem Karola do Italii, Niemiec i Niderlandów. Wówczas to po raz ostatni widział swoje potomstwo dwuletnią Juanę i jej młodszego brata Juana, zmarłego we wczesnym dzieciństwie.

Późniejsze kontakty dyplomaty z rodziną w Hiszpanii dokumentuje jego korespondencja zarówno z Isabellą oraz Juaną, jak i z niemieckimi agentami Welserów na Półwyspie Iberyjskim: Ulrichem Ehingerem, Hieronimem Sailerem i Albrechtem Kuonem, a także z przyjaciółmi dyplomatami: Cornelisem De Schepperem i Johanem Weze. Wszyscy oni przyjaźnili się z posłem polskich władców, a Kuon był ojcem chrzestnym jego córki. Dantyszek początkowo wspierał swoje dzieci i ich matkę finansowo, później zaś, osiadłszy na biskupstwie chełmińskim w Prusach, zaczął snuć plany sprowadzenia córki do siebie. Matce obiecywał dalsze regularne wsparcie (20 dukatów rocznie), ona jednak wolała jednorazową znaczniejszą wypłatę (200 dukatów), co sprawiło, że Dantyszek zaprzestał starań o przyjazd

7 „Innymi zaś przymiotami przypominasz rodzicielkę, / jaśniejącą rodem i skromnością Juanę / Dantiskę, nawet od pysznej Niobe / płodniejszą i szczęśliwszą / za sprawą tak licznego potomstwa pięknego jak róża”, Plutarch, Morales, tł. hiszp. D. Gracián de Alderete, Salamanca 1571, Universidad Complutense, Biblioteca Histórica, sygn. A8, B6, A-Z8, 2A-2N8, 2O10, k. A ver. (tł. na pol. A.S.).

8 Por. A. Skolimowska, Ioannes Dantiscus on the Way ad arcem Virtutis. Representations of the Coat of Arms as a Tool of Self-Creation of a Renaissance Humanist and Diplomat, w: Humanitas. Festskrift till Arne Jönsson, ed. A. M. H. Nilsson, A. Damtoft Poulsen, J. Svensson, Göteborg-Stockholm 2017, s. 443-446, 451-452. 
Juany do Prus. Zarzucił wówczas Isabelli, że pragnie sprzedać córkę i ripostował przewrotnie, że nie można kupić swojej własności, skoro więc Isabella proponuje mu taką transakcję, należy domniemywać, że to nie Dantyszek jest ojcem Juany ${ }^{9}$. Negocjacje utrudniała dodatkowo ogromna odległość między Prusami a Hiszpanią.

W dziesiątym roku życia Juany na scenę wkroczył Diego Gracián de Alderete, sekretarz cesarza Karola V i cesarzowej Izabeli (później w służbie ich syna, króla Hiszpanii Filipa II), tłumacz literatury greckiej i łacińskiej, erazmianista, znany Dantyszkowi jeszcze z czasów działalności dyplomatycznej ${ }^{10}$. Gracián zaręczył się z Juaną w Valladolid w czerwcu 1537 r. $^{11}$, a niespełna rok później - dziewczynka miała wówczas nieco ponad jedenaście lat - poślubił ją ${ }^{12}$. O planach matrymonialnych informował przyszłego teścia, wytaczając m.in. argument, że nędza matki wkrótce skłoni ją do poświęcenia córki nierządowi ${ }^{13}$. Listy szły jednak tak długo, że prośby Graciána o zgodę dotarły do adresata

9 „Per hos annos post discessum meum ex Hyspania plures a te habui litteras, quibus interdum, quamdiu meae videbaris morem gerere voluntati, respondi, cum autem aliud me $<$ di $>$ tabaris, exigens a me, qui nihil tibi debeo, ducentos praesenti pecunia ducatos, respondere distuli. Contendebas enim hoc, quod meum esse asseverabas, ut a te emerem. Idipsum non postulasses a me, si meum fuisset, quis enim hoc, quod suum est, emit? Quandoquidem scis, cum quo in Hispali seu Sivilia prope hortum inclusa commiscebaris: illi, quod suum est, erat mittendum - ego, quod alterius est, eo in casu emere non soleo", CIDTC, IDL 3857.

10 Ibidem, IDL 1538.

11 Ibidem, IDL 1656, IDT 264.

12 Ibidem, IDT 1.

13 „Alioquin exspectaturus eram aequo animo hunc consensum, si recte memini per meas primas litteras abs te petitum, quas trinis exemplis fateris accepisse, maxime cum filia tua id esset aetatis tunc, quae me non ad amorem et libidinem propter formam, sed potius ad misericordiam sui propter pietatem Christianam paternamque amicitiam simplicitatemque morum invitare potuisset. Quibus tantum, dum modis omnibus prospicio, nullis sumptibus peperci idque cum vilius a matre pessima, pauperrima pecuniaeque avidissima in concubinam emere, quam in coniugem redimere potuissem”, ibidem, IDL 1862; „Quandoquidem ipse ab eo tempore, quo Dantiscam uxorem duxi, neque morbo neque alio quopiam laboravi, sed valui valeoque cum uxore et liberis munere Dei Optimi Maximi, qui mihi hoc et aliis hoc genus beneficiis reprehendit opus bonum, quod eius contemplatione tantum operatus sum, dum Dantiscam inopem, egenam, desertam ac miserabiliter derelictam, indotatam uxorem duxi matremque mea pecunia adiutam locavi eo tempore, quo illius pudicitia erat periclitatura, huius autem vita infamia laborabat utraque certe vel fame periturae aut quaestum corporis turpiter facturae, ni praeveniens subvenissem idque contempta alibi dote, quam tunc temporis ingentem potui accepisse”, ibidem, IDL 2969. 
dopiero kilka miesięcy po ceremonii zaręczyn. Wynikły stąd dalsze urazy. Pomimo okazywanego przez Dantyszka niezadowolenia Gracián nie tracił nadziei na akceptację związku i uzyskanie przez Juanę posagu, toteż opisywał szczegółowo ojcu dziewczynki, co się z nią dzieje. Informował, że po zaręczynach powierzył ją opiece swojej matki, Isabelli de Hermosilla, podkreślając, że zadbała ona o wykształcenie i formację duchową Juany tak samo, jak dbała o własną córkę, rówieśniczkę synowej. Niewiele to pomogło w poprawie relacji rodzinnych. Dantyszek obraził się i, jak już wcześniej wspomniano, posagu nie wypłacił.

Tymczasem jego córka dorosła do macierzyństwa i (zgodnie z przytoczonym powyżej cytatem) osiągnęła $\mathrm{w}$ nim znakomite rezultaty potomstwo jej i Graciána było rzeczywiście liczniejsze niż potomstwo Niobe. Cristóbal Márquez, biograf najsławniejszego chyba z wnuków Dantyszka, spowiednika św. Teresy z Ávili, ojca Jeronima Graciána Dantisco OCD, wylicza dwadzieścioro dzieci Diega i Juany, spośród których aż trzynaścioro było mu znanych z imienia i dożyło wieku dojrzałego ${ }^{14}$. Prócz Jeronima (1545-1614) należą do nich m.in. wspomniany już Antonio (1542-1576), Lucas (1543-1587) i Tomas Gracián Dantisco (1558-1621) - wszyscy trzej będący prominentnymi literatami i urzędnikami w służbie hiszpańskiego dworu królewskiego.

W tymże samym 1571 r., w którym wyszedł drukiem wspomniany już przekład Moraliów Plutarcha, staraniem Diego Graciána ukazała się, także w Salamance, pierwsza znana nam hiszpańska edycja Hymnów religijnych autorstwa Jana Dantyszka. Hymny, opublikowane po raz pierwszy - jak wspomniano na początku artykułu anonimowo w Krakowie na kilka miesięcy przed śmiercią autora $(1548)^{15}$, były już przedmiotem wielu analiz i dyskusji naukowych ${ }^{16}$.

14 Por. C. Márquez, Excelencias, vida y trabajos del padre fray Jerónimo Gracián de la madre de Dios, carmelita, Madrid 2012, s. 84-96; por. A. del Marmol, Excellencias, vida, y trabaios del padre fray Geronimo Gracian de la Madre de Dios, Carmelita, Madrid 1619, k. 4ver.-11rec., egz. Biblioteca Nacional de España, sygn. U/918.

15 Dantyszek, Hymni 1548.

16 Por. A. Moss, Johannes Dantiscus, Hymn-Writer, w: Munera philologica. Georgio Starnawski ab amicis, collegis, discipulis oblata, ed. K. A. Kuczyński, Z. J. Nowak, H. Tadeusiewicz, Łódź 1992, s. 155-162; P. Urbański, Natura i taska w poezji polskiego baroku: okres potrydencki. Studia o tekstach, Kielce 1996, s. 18-41 (rozdz. „Hymny Jana Dantyszka - próba interpretacji”); E. Llamas Martínez, Una rareza bibliográfica. Edición española de poemas religiosos del humanista polaco Juan Dantisco (1571, 1576), „Monte Carmelo”, 106, 1998, s. 275-291; P. Urbański, Between Ignatianism and Stoicism (Dantiscus, Sarbievius), w: Wątki 
Pewne aspekty edycji hiszpańskiej umknęły jednak oku badaczy, którzy koncentrowali się przede wszystkim na wymiarze teologicznym i literackim hymnów, konstatując jedynie fakt (odnotowany w licencjach na druk), że istniało jeszcze jedno wydanie hiszpańskie sprzed 1571 r., którego żaden egzemplarz nie jest znany ${ }^{17}$, oraz pobieżnie opisując różnice między zawartością edycji hiszpańskich oraz krakowskiej. Odmienności te w zasadzie nie dotyczą zawartości samych hymnów, lecz tekstów towarzyszących.

Edycja krakowska, w przeciwieństwie do hiszpańskich, nie zawiera świadectw zgodności z doktryną katolicką, licencji królewskiej na druk ani, co oczywiste, przedmowy skierowanej przez Diego Graciána de Alderete do czytelnika. Inicjatywą wydawcy hiszpańskiego było także umieszczenie wśród tekstów wstępnych Genethliaconu, napisanego dla Dantyszka na jego trzydzieste pierwsze urodziny (1516) przez Caspara Ursinusa Veliusa ${ }^{18}$, a na końcu publikacji - poematu okolicznościowego pióra Dantyszka, zatytułowanego De nostrorum temporum calamitatibus, który powstał przy okazji pojednania cesarza Karola V z papieżem Klemensem VII w 1529 r. i koronacji cesarskiej w Bolonii w kolejnym roku ${ }^{19}$. Żaden $\mathrm{z}$ tych dość obszernych utworów nie

neostoickie $w$ literaturze polskiego renesansu i baroku, ed. P. Urbański, Szczecin 1999, s. 173-189; idem, Theologia fabulosa. Commentationes Sarbievianae, Szczecin 2000, s. 97-98; idem, Joannes Dantiscus and Italian Neo-Latin Poetry, w: Acta Conventus Neo-Latini Cantabrigiensis, ed. J.-L. Charlet, Tempe (AZ) 2003, s. 555-563; A. Moss, Joannes Dantiscus (1485-1548): Hymns in Context, w: Pietas Humanistica. Neo-Latin Religious Poetry in Poland in European Context, ed. P. Urbański, Frankfurt am Main 2006, s. 71-82.

17 Oto odnośny fragment licencji na druk: „un libro intitulado hymnos ecclesiasticos y Sylva de temporum calamitatibus, que otra vez con licencia nuestra avia sido impresso"; w dalszej części listu licencyjnego zezwala się na sprzedaż książki dopiero po porównaniu jej z poprzednią edycją i stwierdzeniu, że jest dokładnie taka sama; Dantyszek, Hymni 1571, k. A ver.-A rec.

18 „C. VRSINI VELII GENETHLIACON Ioannis Dantisci poetae clarissimi”, w: C. Ursinus Velius, POEMATUM LIBRI QUINQUE, Basileae 1522, Universidad Complutense, Biblioteca Historica, sygn. a-z4, A-I4 (dalej: Ursinus), k. q-q ; Dantiscus, Hymni 1571, 1576, k. A ver.-A ver.

19 Pierwsze wydanie: J. Dantyszek, Ad Clem(entem) VII. Po(n)t(ificem) Max(imum) et Carolu(m) V. Imp(eratorem) Aug(ustum) De nostrorum te(m)porum calamitatibus Sylua Bonon(iae) aedita. IX. Decemb(ris) M. D. XXIX., Bononiae 1530, BJ, sygn. St. Dr. Cim. 5354 (dalej: Dantyszek, Sylva); jeszcze w tym samym 1530 r. liczne przedruki - w Krakowie, Gandawie, Kolonii, Antwerpii; jeżeli pominąć epigramat wstępny (odmianki którego stanowią przedmiot analizy w niniejszym artykule), w edycjach hiszpańskich tekst tego poematu, podobnie jak i główny tekst hymnów, nie odbiega znacząco od pierwodruku. 
został zasygnalizowany na stronie tytułowej tomiku, mimo że w istocie nie jest on przedrukiem edycji krakowskiej Hymni aliquot ecclesiastici, lecz kompilacją trzech różnych druków.

Układ typograficzny obu znanych nam druków hiszpańskich (1571, 1576) jest identyczny, co zgadza się z zaleceniem zawartym w licencjach na druk, zezwalających na sprzedaż książek dopiero po porównaniu ich z poprzednią edycją i stwierdzeniu, że są dokładnie takie same („el dicho libro no se pueda vender ni venda sin que primero se trayga al nuestro consejo juntamente con el dicho original, para que se vea si la dicha impression esta conforme a el") ${ }^{20}$. Obie licencje zawierają zasadniczo tę samą treść, różnią się jednak w szczegółach. W licencji na edycję z 1571 r. (datowanej 22 II 1570) książka określona jest jako „un libro intitulado hymnos ecclesiasticos y Sylva de temporum calamitatibus, que otra vez con licencia nuestra avia sido impresso". Ten zapis pozwolił badaczom na domniemanie istnienia wcześniejszej edycji hiszpańskiej, opublikowanej zapewne ok. 1566 r. W licencji na edycję z 1576 r. (datowanej 5 V 1575) odniesienie do wzorca jest sformułowane następująco: „a vuestro pedimiento os aviamos dado licencia, para que pudiessedes [sic!] imprimir un libro intitulado los Hymnos Ecclesiasticos, y porque auia falta del dicho libro y era vtil y prouechoso". W obydwu jednak licencjach oryginał, z którym ma być porównana nowa edycja, opisano jako „original [--] que va rubricado y firmado al cabo de Pedro del Marmol nuestro scrivano de camara" 21 . Przeprowadziłam dokładną analizę porównawczą odmianek tekstowych hymnów zawartych we wszystkich trzech znanych edycjach $(1548,1571,1576)$. Analiza ta prowadzi do wniosku, że edycja z 1576 r. nie kopiuje publikacji z1571 r., potwierdza natomiast bez żadnych wątpliwości istnienie zaginionego wydania, które było podstawą obydwu znanych nam edycji hiszpańskich. Świadczy o tym obecność sporej liczby zarówno identycznych, jak i zupełnie odmiennych wariantów tekstu (wszystkie one mają charakter omyłek kopisty lub składu) tych dwóch edycji w stosunku do edycji krakowskiej ${ }^{22}$.

20 Tekst za edycją z 1571 r. W edycji z 1576 r. sformułowanie „el dicho libro no se pueda vender ni venda sin que primero" zastąpiono krótszym, ale równoważnym zwrotem: „antes que se venda”, Dantyszek, Hymni 1571, 1576, k. $A_{2}$ ver. $-A_{3}$ rec.

21 Ibidem.

22 Odmianki te zostały wykazane w internetowej edycji korpusu tekstów Dantyszka, CIDTC. 
Istotne różnice w zawartości wydania krakowskiego i wydań hiszpańskich ukazuje poniższa tabela:

\begin{tabular}{|c|c|c|c|}
\hline \multicolumn{2}{|c|}{ Kraków 1548} & \multicolumn{2}{|c|}{ Salamanka [przed 1571], 1571, 1576} \\
\hline$\left[\mathrm{A}_{1}\right.$ rec. $]$ & $\begin{array}{l}\text { tytuł; informacja } \\
\text { wydawnicza (Kraków, } \\
\text { wdowa po Hieronimie } \\
\text { Wietorze, 1548) }\end{array}$ & {$\left[\mathrm{A}_{1} \mathrm{rec}.\right]$} & $\begin{array}{l}\text { tytuł; informacja o autorstwie Dantyszka; } \\
\text { informacja wydawnicza (licencja, } \\
\text { Salamanka, Mathias Gastius, } 1571 \text { / } \\
\text { Gaspar a Portonariis, 1576) }\end{array}$ \\
\hline & & {$\left[\mathrm{A}_{2} \mathrm{rec}.\right]$} & $\begin{array}{l}\text { trzy świadectwa, że nie jest to książka } \\
\text { heretycka }\end{array}$ \\
\hline & & $\begin{array}{l}{\left[\mathrm{A}_{2} \text { ver. }\right]-} \\
\mathrm{A}_{3} \text { rec. }\end{array}$ & $\begin{array}{l}\text { Licencja na druk - list króla Filipa II, } \\
\text { Madryt, } 22 \text { II 1570; Madryt, } 5 \text { V 1575; } \\
\text { listy różnią się w drobnych szczegółach }\end{array}$ \\
\hline & & $\begin{array}{l}\mathrm{A}_{4} \text { rec.- } \\
\mathrm{A}_{6} \text { rec. } \\
\end{array}$ & $\begin{array}{l}\text { Prologus - Przedmowa Diego Graciána } \\
\text { do czytelnika }\end{array}$ \\
\hline & & {$\left[\mathrm{A}_{6}\right.$ ver. $]$} & $\begin{array}{l}\text { AD LECTOREM [wiersz wstępny autorstwa } \\
\text { Dantyszka do jego poematu De nostrorum } \\
\text { temporum calamitatibus silva, tekst zmieniony] }\end{array}$ \\
\hline $\mathrm{A}_{\mathrm{ii}} \mathrm{rec}$ & $\begin{array}{l}\text { PETRUS ROYZIUS } \\
\text { MAUREUS AD } \\
\text { LECTOREM }\end{array}$ & {$\left[\mathrm{A}_{6}\right.$ ver. $]$} & $\begin{array}{l}A D E U N D E M[\text { utwór autorstwa } \\
\text { Rojzjusza] }\end{array}$ \\
\hline \multirow[t]{2}{*}{$\mathrm{A}_{\mathrm{ii}} \mathrm{rec}$} & $I D E M$ & $\mathrm{~A}_{7} \mathrm{rec}$. & $\begin{array}{l}\text { IDEM [utwór autorstwa Rojzjusza, } \\
\text { tekst zmieniony] }\end{array}$ \\
\hline & & $\begin{array}{l}{\left[A_{7} \text { ver.- }\right.} \\
\left.A_{8} \text { ver. }\right]\end{array}$ & $\begin{array}{l}\text { C. URSINI VELII GENETHLIACON } \\
\text { Ioannis Dantisci viri clarissimi } \text { [tekst } \\
\text { zmieniony] }\end{array}$ \\
\hline$A_{2}$ ver. & $\begin{array}{l}\text { herb Samuela } \\
\text { Maciejowskiego i epigram } \\
\text { P. Rojzjusza o herbie }\end{array}$ & & \\
\hline $\begin{array}{l}A_{3} \text { rec.- } \\
{\left[\mathrm{A}_{4}\right] \text { ver. }}\end{array}$ & $\begin{array}{l}\text { list Hozjusza do Samuela } \\
\text { [Maciejowskiego], Kraków, } \\
10 \text { VII } 1548\end{array}$ & $\begin{array}{l}{\left[A_{9} \text { rec. }\right]-} \\
{\left[A_{10} \text { ver. }\right]}\end{array}$ & $\begin{array}{l}\text { list Hozjusza do Samuela [Maciejowskiego], } \\
\text { Kraków, } 10 \text { VII } 1548 \text { [tekst ocenzurowany] }\end{array}$ \\
\hline \multirow[t]{4}{*}{$\begin{array}{l}\text { Brec.- } \\
\mathrm{P}_{3} \text { ver. }\end{array}$} & hymny Dantyszka & $\begin{array}{l}\text { 1rec.- } \\
\text { 49ver. }\end{array}$ & hymny Dantyszka \\
\hline & & $\begin{array}{l}\text { 50rec.- } \\
\text { 58rec. }\end{array}$ & $\begin{array}{l}{[--] \text { IOANNIS DANTISCI }[--]} \\
\text { De temporum calamitatibus Sylva }\end{array}$ \\
\hline & & 58rec. & $\begin{array}{l}\text { stopka wydawnicza: Salamanticae. Typis } \\
\text { Mathiae Gastii. } 1571 \text { / Salamanticae. } \\
\text { Excudebat Gaspar a Portonariis. } 1576\end{array}$ \\
\hline & & $\begin{array}{l}{[59] \text { rec.- }} \\
\text { ver. }\end{array}$ & Erratae [tylko w wydaniu z 1576] \\
\hline
\end{tabular}

Pierwszą znaczącą różnicą jest podanie informacji o autorstwie Hymnów. Motywacja wydaje się tu oczywista - chodzi o promowanie wydawcy jako powinowatego, a jego potomstwa jako wnuków twórcy 
„książeczki godnej zaiste, by znaleźć się w rękach wszystkich chrześcijan o pobożnych sercach” („libellus [--] dignus sane, qui manibus omnium Christianorum versetur, quibus pietas cordi est") ${ }^{23}$ - cytat ten pochodzi z prologu Graciána skierowanego do czytelnika. Również i sam prolog uwydatnia związki wydawcy z autorem ${ }^{24}$.

Funkcja świadectw zgodności zawartości książki z obowiązującą doktryną i licencji na druk jest przede wszystkim techniczna: były one niezbędne do publikacji drukiem w katolickiej Hiszpanii, szczególnie w czasach potrydenckich.

Pierwszym naprawdę zaskakującym czytelnika elementem jest zamieszczony w edycjach hiszpańskich bezpośrednio po prologu wiersz zatytułowany $A D$ LECTOREM. Jest to epigramat napisany przez Dantyszka jako wstęp do poematu De nostrorum temporum calamitatibus silva, publikowanego przez Graciána po tekście Hymnów. Wersja epigramatu podana w hiszpańskich edycjach zawiera istotne zmiany $\mathrm{w}$ stosunku do autorskiego oryginału. Pierwotnie podmiotem lirycznym był autor opowiadający czytelnikowi o genezie utworu i zachęcający do lektury. Gracián niewątpliwie wykorzystał fakt, że Dantyszek dopiero w ósmym i w szesnastym wersie epigramatu zdradza tożsamość pojawiającego się na początku Sarmata vates, utożsamiając go $\mathrm{z}$ autorem wiersza poprzez zastosowanie pierwszej osoby gramatycznej. W edycjach hiszpańskich pierwsza osoba została konsekwentnie zastąpiona trzecią, co sprawia, że czytelnik skłonny jest przypisać autorstwo wiersza nie autorowi książki, lecz jej wydawcy.

$\mathrm{Na}$ zmiany te nie zwrócił do tej pory uwagi żaden z badaczy zajmujących się tym tematem. Wyglądają one następująco:

\begin{tabular}{|l|l|l|}
\hline Numer wersu & Wersja autora $(1530,1531)^{25}$ & Wersja wydawcy $(1571,1576)^{26}$ \\
\hline $7-8$ & $\begin{array}{l}\text { Hesperice sic forte loqui, dum missus } \\
\text { utramque } \\
\text { Hesperiam peragro, me didicisse puta! }\end{array}$ & $\begin{array}{l}\text { Hesperice sic forte loqui, dum missus } \\
\text { utramque } \\
\text { Hesperiam peragrat, hunc didicisse puta! }\end{array}$ \\
\hline 16 & $\begin{array}{l}\text { Cum sensum teneas, nil ego verba } \\
\text { moror. }\end{array}$ & $\begin{array}{l}\text { Qui sensum teneas, tunc quoque verba } \\
\text { iuvent. }\end{array}$ \\
\hline
\end{tabular}

23 Dantyszek, Hymni 1571, 1576, k. A 5 rec.

24 Ibidem, k. A rec.-A 6 rec.

25 Dantyszek, Sylva, k. A ver.

26 Dantyszek, Hymni 1571, 1576, k. A 6 ver. 
Po tym epigramacie następują dwa kolejne, zatytułowane $A D$ EUNDEM (DO TEGOŻ) oraz IDEM (TO SAMO), zaczerpnięte z krakowskiej edycji Hymnów. Czytelnik ponownie odnosi wrażenie, że autorem tych epigramatów jest wydawca, podczas gdy w edycji krakowskiej są one umieszczone pod nazwiskiem hiszpańskiego humanisty Piotra Rojzjusza (Pedro Ruiz de Moros, Petrus Royzius Maureus). Tekst tych epigramatów w edycji polskiej i hiszpańskich pozostaje identyczny z wyjątkiem ostatniego dystychu drugiego z nich. W wydaniu krakowskim czytamy:

Quam doctus sene Maeonio potes esse relecto,

Tam bonus hoc lecto, tam pius esse potes

- co oznacza, że lektura Hymnów może uczynić czytelnika tak dobrym i pobożnym, jak uczonym może go uczynić lektura całego Homera („senex Maeonius”). Tymczasem obie edycje hiszpańskie zamiast słowa „relecto” dają „relicto”, sugerując w ten sposób, że czytelnik stanie się mądry, jeżeli Homera porzuci! Inspiracją do wprowadzenia tej zmiany był zapewne początek epigramatu, $\mathrm{w}$ którym pobożne dziełko Dantyszka zostało przeciwstawione „kłamstwom ubiegłego wieku” „aevi ficta prioris" i „ohydnym potworom dawnych czasów” - „foeda vetustatis monstra". Eposy Homera zostały, jak się zdaje, sklasyfikowane jako jedno $\mathrm{z}$ owych starożytnych zmyśleń (zgodnie $\mathrm{z}$ toposem figmenta poetarum vs vera poesis). Mogła to być oczywiście przypadkowa literówka, lecz za chwilę zobaczymy, że nie jest to jedyna zmiana o podobnym charakterze.

Po trzech epigramatach skierowanych do czytelnika umieszcza Gracián utwór, który przywoływał już wcześniej w prologu jako świadectwo pobożności autora Hymnów i Sylwy, a mianowicie Genethliacon dla Dantyszka pióra Caspara Ursinusa Veliusa ${ }^{27}$. Ma ono formę proroctwa wygłaszanego przez Apollina w chwili narodzin Dantyszka. Zawiera pochwałę cech fizycznych i umysłowych przychodzącego na świat chłopca, opis jego przyszłych sukcesów jako poety i dyplomaty, a także podróży, jakie ma w przyszłości odbyć, m.in. pielgrzymki do Ziemi Swiętej. Ta wersja Genethliaconu, którą posłużył się Gracián, różni się znacząco od autorskiej wersji Ursinusa. W opisie tych różnic pominę nieistotne literówki, koncentrując się jedynie na znaczących modyfikacjach.

27 Ibidem, k. A 7 ver.-A $A_{8}$ ver. 
W tytule Genethliaconu Dantyszek określony został przez Ursyna jako poeta clarissimus, co Gracián zamienił na vir clarissimus, może pragnąc podkreślić powagę opisywanej w wierszu osoby.

W dystychu brzmiącym „Prima tuos ignes recitabunt ludicra: toto / Prospera versiculis vivet in orbe tuis” 28 Gracián zastąpił słowa „tuos ignes” słowami „notos lusus”. Dystych ten pierwotnie odnosił się bez wątpienia do epigramatów miłosnych, którymi Dantyszek miał rozsławić na cały świat swoją kochankę o imieniu Prospera (epigramaty te zaginęły, istnienie kochanki o tym imieniu jest jednak poświadczone w korespondencji Dantyszka ${ }^{29}$. Gracián poprzez wprowadzoną zmianę zatarł erotyczny charakter młodzieńczej twórczości teścia. Ułatwił mu to fakt, że rzeczownik „Prospera” stoi na początku linijki, mógł więc być traktowany jako pospolity przymiotnik, mimo że rozpoczyna się wielką literą. Zmiana ta ma wyraźny charakter cenzury obyczajowej. Warto przy tym zwrócić uwagę, że ingerencja ta powoduje błąd w prozodii wiersza (dwie długie sylaby „nōtos” w miejsce krótkiej i długiej „tuos”).

Kolejną interwencją Graciána jest uzupełnienie zapewne nie dość jego zdaniem uwypuklonego przez autora, gdyż mieszczącego się w zaledwie trzech dystychach, opisu pobytu Dantyszka w Ziemi Świętej:

Et Syriae populos, et inhospita vasta videbis,

Qua non aequoreo tutius extat iter.

Quin et adorabis sacrum, quo condita passi

Lurida sarcophago membra fuere Dei,

Quaeque Palaestinas loca sunt veneranda per oras

Bethlemiumque larem Calvariaeque solum ${ }^{30}$

trzema dystychami wyjętymi z zupełnie innego utworu, a mianowicie z Ad amicos Hierosolymam proficiscentes Giovanniego Pontana:

Felicemque locum, iacuit quo rector Olympi

Et quam divino sanguine tinxit humum.

Hic ubi, crudeli traiectus brachia ferro est,

Fixit et immeritos cuspis adacta pedes,

Hausit et immeritum latus heu ferratile telum,

Diluit et fusus crimina nostra cruor $^{31}$.

28 Ursinus, 1. 21-22.

29 List Jana Zambockiego do Jana Dantyszka, Kraków, 16 VIII 1527 r.: „Prosperam tuam, dum castra sequitur, Leopoli esse mortuam”, CIDTC, IDL 362.

30 Ursinus, 1. 48-52.

31 G. Pontano, Amorum libri duo; De amore coniugali libri tres; Tumulorum libri duo; De divinis laudibus liber unus; Hendecasyllaborum seu Baiarum libri duo; 
Oczywiście uzupełnienie to nie zostało w żaden sposób zasygnalizowane przez wydawcę.

Ostatnią istotną ingerencję $\mathrm{w}$ tekst pierwotny stanowi usunięcie ostatnich sześciu dystychów tego 88-wierszowego utworu: w edycjach Graciána kończy się on odejściem Feba sprzed drzwi rodzącej i sceną, kiedy to Parki zaczynają prząść nici życia Dantyszka. Jest to niewątpliwie zgrabne zakończenie, ale w oryginale znajduje się jeszcze opis porodu, błogosławieństwo bogów (w tym Junony jako patronki porodów) dla noworodka oraz życzenia i wiwaty, jakie wznoszą na cześć jubilata przyjaciele, a wśród nich także autor poematu, podczas urodzinowego przyjęcia. Oto fragment usunięty przez wydawcę:

Solvebat magnum Lucina facillima partum.

Et positum est utero dulce parentis onus.

Natus es in lucem, lux o generosa tuorum.

Felicem o genium terque quaterque tuum.

Natus es auspicibus diis et Iunone secunda.

Fila quater vitae terque beata tuae.

Sed iam, convivae, plausum date. Pocula sumat

Quisque simul mecum et talia voce sonet:

Vivat io Dantiscus, io laetum exigat aevum, Vivat io patriae, vivat io ille suis.

Est bene, non votis optamus inanibus ista

Risit, et optatis annuit ipse deus.

Można jedynie domniemywać, że takie zakończenie, zdaniem Graciána, zanadto akcentowało świecki charakter uroczystości urodzin autora Hymnów religijnych, a może też zawierało zbyt wiele elementów pogańskich. Jest też możliwe, że Gracián usunął ostatnie sceny, jako dotyczące dawno minionych realnych okoliczności powstania utworu, tak aby czytelnik zachował w pamięci przede wszystkim obraz Dantyszka stojącego na piedestale stworzonym przez przepowiednię Apollina.

O tym, że Diego Gracián de Alderete osobiście dokonywał zmian redakcyjnych w utworze Ursinusa świadczy nie tylko jego nazwisko umieszczone w liście licencyjnym króla Filipa II oraz autorstwo prologu, lecz także zachowany egzemplarz pierwszej edycji Genethliaconu,

Iambici versus de obitu Lucii filii; Lyrici versus ad res varias pertinentes; In calce libri duo quibus titulus est Eridanus, Florence 1514, Biblioteca Pública del Estado, Biblioteca de Guadalajara, sygn. FA00404(2), k. 102; idem, Carmina: ecloghe, elegie, liriche, ed. J. Oeschger, Bari 1948, s. 275. 
zawierający własnoręczne notatki Graciána, zgodne z wprowadzonymi zmianami: poprawkę słowa „tuos” na „notos” oraz cały dodany fragment wiersza Pontana, zanotowany w stosownym miejscu na marginesie ${ }^{32}$.

Ostatnim elementem omawianych edycji Hymnów, który zawiera interwencje zięcia Dantyszka, jest list dedykacyjny Stanisława Hozjusza (podówczas kanonika warmińskiego, później biskupa i kardynała, aktywnego twórcy i egzekutora reformy trydenckiej Kościoła rzymskiego) do biskupa krakowskiego i kanclerza wielkiego koronnego Samuela Maciejowskiego, datowany w Krakowie 10 lipca $1548 \mathrm{rr}^{33}$

W liście tym, pełniącym funkcję przedmowy do krakowskiej edycji Hymnów, Hozjusz stwierdza m.in., że w autorze Hymnów zaszła zmiana, związana z przeminięciem płochej młodości i porzuceniem niemoralnego dworu ${ }^{34}$ :

32 Ursinus, egzemplarz dostępny w internecie: https://books.google.pl/books?id= kuE59vwQezIC\&printsec=frontcover\&hl=pl\&source=gbs_ge_summary_r\&ca$\mathrm{d}=0 \# \mathrm{v}=$ onepage\&q\&f=false ( $11 \mathrm{~V}$ 2018); w egzemplarzu tym marginalia znajdujemy wyłącznie przy tym jednym wierszu, poświęconym Dantyszkowi (jeśli nie liczyć kilku zaznaczeń w postaci pionowej kreski bądź krzyżyka, pojawiających się przy innych utworach). Na pustej stronie na końcu omawianego druku, tą samą ręką, co marginalia towarzyszące Genethliaconowi, wpisany został wiersz Luigiego Bigiego Pittoria De Christo Crucifixo. Pod wierszem Pittoria znajduje się adnotacja inną ręką (niewątpliwie należącą do któregoś z licznych dzieci Graciána i Juany Dantiski): „de mano de mi Padre el Secr(etari)o Di(eg)o Gracian” [=ręką mojego ojca, sekretarza Diego Graciána] (tą samą ręką pisane są także listy oryginalne Diego Graciána do Dantyszka). Oprócz wspomnianej zmiany tuos na notos i fragmentu wiersza Pontana, adnotacje Graciána po części objaśniają niektóre trudniejsze określenia wzmiankowanych w wierszu postaci starożytnych, po części zaś - co znacznie ciekawsze - odnoszą się do osoby Dantyszka. Marginalia Graciána zostały odnotowane w aparacie krytycznym do edycji Genethliaconu zamieszczonej w aneksie do mojego artykułu Records of Friendship on the Threshold of a Diplomatic Career. Nardino Celinese's Propempticon o Caspar Ursinus Velius' Genethliacon, Poems Dedicated to Ioannes Dantiscus, w: De amicitia. Transdisciplinary Studies in Friendship, ed. K. Marciniak, E. Olechowska, Warsaw 2016, s. 327-347.

33 Dantyszek, Hymni 1571, 1576, k. A A rec.-A $_{10}$ ver.; Dantyszek, Hymni 1548,

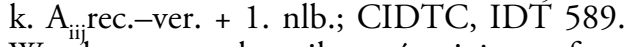

34 Wątek ten przedstawiłam również w referacie Ex Saulo Paulus, ex persecutore apostolus? Duchowa przemiana biskupa Dantyszka w świetle nowych źródet, wygłoszonym na konferencji „Reformacja w Prusach” (Olsztyn 2017). Ponieważ w momencie opracowywania niniejszego tekstu nie było jasności, czy planowany tom materiałów konferencyjnych ukaże się drukiem, pozwoliłam sobie wykorzystać tutaj niektóre fragmenty tego referatu; wspomniane materiały konferencyjne zostały ostatecznie opublikowane w „Komunikatach Mazursko-Warmińskich”, 2 (312), 2021. 
Est autem haec admirabilis et stupenda quaedam mutatio dexterae Excelsi, quod qui libelli huius auctor est, is eadem aliquando fuit infirmitate praeditus, qua sumus nos. Nam et iuvenis ab iis, quae aetas illa fert, non abhorruit, et bonam aetatis suae partem in aula consumpsit, cuiusvis rei potius, quam virtutis, magistra, ita ut longe tum ab illo distaret, quem eum nunc esse videmus ${ }^{35}$.

Ten ostatni fragment, w którym Hozjusz precyzuje, że dwór „uczy raczej wszystkiego innego niż cnoty”, a następnie podkreśla przemianę, jaka zaszła w Dantyszku, został w edycjach hiszpańskich pominięty, podobnie jak i następujące dalej nawiązanie do opisanej w Dziejach Apostolskich przemiany Szawła w Pawła:

Dicas: ex Saulo Paulum, ex persecutore factum apostolum.

Porównanie to, wyrwane z kontekstu, sprowokowało badaczy do pochopnych konstatacji, jakoby Dantyszek, będąc już biskupem, gwałtownie nawrócił się pod wpływem Hozjusza, a przed swoją przemianą prześladował Kościół rzymski, opowiadając się po stronie Lutra. Słowa Hozjusza nie dają jednak podstaw do takiego mniemania, pisze on bowiem dalej (Gracián zaś dalej cenzuruje):

\section{Nam ut nos vita nunc nostra persequimur Ecclesiam Dei, sic et ille persecutus est olim.}

Nie ma najmniejszych wątpliwości, że Hozjusz nie zarzucałby ani sobie, ani tym bardziej Maciejowskiemu „prześladowania Kościoła Bożego" w znaczeniu sprzyjania reformacji. Nie oskarża o to zatem także Dantyszka. Przemiana, którą ma na myśli, dotyczy wyłącznie kwestii obyczajowych, nie zaś światopoglądowych. Oto Dantyszek porzuca sprawy świata dla spraw ducha. To właśnie odwrót od rzeczy świeckich w ogóle, a nie sprzyjanie tej czy innej religii, ma na myśli Hozjusz, pisząc dalej o Dantyszku:

Tandem vero, misericordia Dei non postremum honoris gradum in ea consecutus, exuit veterem hominem, novum induit, et quanto saeculi quondam, tanto nunc Christi amore exarsit, ut non alia magis in re affecta in hac et aetate, et valetudine sua, quam in iugi Christi beneficiorum meditatione versetur ${ }^{36}$.

35 Dantyszek, Hymni 1548, k. A $\mathrm{iij}_{\mathrm{ij}}$ rec.-ver. Opuszczenia dokonane przez Graciána tu i w dalszej części artykułu zasygnalizowano wyboldowaniem.

36 Ibidem k. A iij ver. 
Słowa „porzucił starego człowieka i wdział nowego”, będące bezpośrednim nawiązaniem do Listu św. Pawła do Kolosan, Gracián zastępuje w swoich edycjach krótkim „est”. Nieco dalej wydawca hiszpański znów usuwa z tekstu Hozjusza przytoczenie ze św. Pawła, tym razem $z$ Listu do Rzymian, ostrzegające przed pochopnym osądzaniem cudzych grzechów:

\section{Quis ergo est, qui iudicare deinceps audeat servum alienum, cum quem certum etiam sit multis nunc esse peccatis obnoxium, qualis ad vesperam sit futurus, certum esse queat nemini ${ }^{37}$.}

Teksty św. Pawła zajmowały poczesne miejsce w dysputach teologów protestanckich. A zatem to, co młody jeszcze i daleki od późniejszej gorliwości kontrreformatorskiej Hozjusz traktował zapewne jako niewinne aluzje do rozważań św. Augustyna o porzuceniu pychy na rzecz pokory ${ }^{38}$, dwadzieścia lat później Graciánowi musiało nieodparcie kojarzyć się z luteranizmem. Tego rodzaju asocjacji hiszpański humanista niewątpliwie pragnął uniknąć.

Widzimy zatem, że większość zmian i skrótów wprowadzonych przez Graciána do tekstów wstępnych jego edycji Hymnów miała charakter moralizatorsko-cenzorski. Ingerencje te mogły być rezultatem zarówno lęku wydawcy przed hiszpańską inkwizycją, jak i obawy przed zgorszeniem pobożnego czytelnika. Obie te pobudki nie wykluczają innej, moim zdaniem naczelnej motywacji: pragnienia wystawienia pomnika, a zarazem świadectwa nieskazitelnej moralności ojcu żony i - co za tym idzie - także jej samej i wspólnemu potomstwu. Dziełko, o czym świadczą kolejne wydania, niewątpliwie dobrze się sprzedawało, wspomagając budżet domowy wydawcy, permanentnie - jeśli wierzyć jego własnym zapewnieniom - niewystarczający. Równocześnie mogło stanowić swoistą wizytówkę dla jego synów i córek. Najstarsze z dzieci w momencie ukazania się pierwszej, zaginionej, edycji hiszpańskiej stały właśnie u progu dorosłości. Hymni aliquot ecclesiastici Dantyszka wydane staraniem Diego Graciána de Alderete byłyby zatem podwójnym - materialnym i moralnym zaległym posagiem Juany Dantiski, „wypłaconym” jej przez ojca zza grobu wiele lat po śmierci.

37 Ibidem, k. $A_{\text {iij }}$ ver. i nast. strona nlb.

38 Augustyn, Enarrationes in Psalmos, 72.10-11; idem, De spiritu et littera liber unus, 7.12; idem, Confessiones, 8.4.9. 


\section{Bibliografia}

\section{Źródła}

Augustyn, Confessiones, 8.4.9

Augustyn, De spiritu et littera liber unus, 7.12

Augustyn, Enarrationes in Psalmos, 72.10-11

Corpus of Ioannes Dantiscus' Texts \& Correspondence / Korpus Tekstów i Korespondencji Jana Dantyszka, ed. A. Skolimowska, M. Turska, with collaboration of K. Jasińska-Zdun, dantiscus.al.uw.edu.pl (9 I 2020)

Dantyszek J., Ad Clem(entem) VII. Po(n)t(ificem) Max(imum) et Carolu(m) V. Imp(eratorem) Aug(ustum) De nostrorum te $(m)$ porum calamitatibus Sylua Bonon(iae) aedita. IX. Decemb(ris) M. D. XXIX., Bononiae 1530

[Dantyszek J.], HYMNI ALIQUOT ECCLESIASTICI, VARIIS versuum generibus, de Quadragesimae Ieiunio, \& sex eius diebus Dominicis, deq(ue) horis Canonicis Christi Passionis tempore. Et de Resurrectione, Ascensione, Spiritussancti missione, Matreq(ue) gloriosissima Maria Virgine, recens aediti, Cracoviae 1548

Dantyszek J., HYMNI ALIQUOT ECCLESIASTICI, VARIIS VERSUUM GENERIBUS, DE Quadragesimae Ieiunio, \& sex eius diebus Dominicis, deque horis canonicis, Christi passionis tempore, \& de resurrectione, Ascensione, Spiritus Sancti missione, matreque gloriosissima Maria virgine, recens aediti, Salamanticae 1571, 1576

Marmol A. del, Excellencias, vida, y trabaios del padre fray Geronimo Gracian de la Madre de Dios, Carmelita, Madrid 1619

Márquez C., Excelencias, vida y trabajos del padre fray Jerónimo Gracián de la madre de Dios, carmelita, Madrid 2012

Plutarch, Morales, tł. hiszp. D. Gracián de Alderete, Salamanca 1571

Pontano G., Amorum libri duo; De amore coniugali libri tres; Tumulorum libri duo; De divinis laudibus liber unus; Hendecasyllaborum seu Baiarum libri duo; Iambici versus de obitu Lucii filii; Lyrici versus ad res varias pertinentes; In calce libri duo quibus titulus est Eridanus, Florentiae 1514

Pontano G., Carmina: ecloghe, elegie, liriche, ed. J. Oeschger, Bari 1948

Ursinus Velius C., POEMATUM LIBRI QUINQUE, Basileae 1522

\section{Opracowania}

Llamas Martínez E., Una rareza bibliográfica. Edición española de poemas religiosos del humanista polaco Juan Dantisco (1571, 1576), „Monte Carmelo", 106, 1998, s. 275-291

Moss A., Joannes Dantiscus (1485-1548): Hymns in Context, w: Pietas Humanistica. Neo-Latin Religious Poetry in Poland in European Context, ed. P. Urbański, Frankfurt am Main 2006, s. 71-82 
Moss A., Johannes Dantiscus, Hymn-Writer, w: Munera philologica. Georgio Starnawski ab amicis, collegis, discipulis oblata, ed. K. A. Kuczyński, Z. J. Nowak, H. Tadeusiewicz, Łódź 1992, s. 155-162

Skolimowska A., Ex Saulo Paulus, ex persecutore apostolus? Duchowa przemiana biskupa Dantyszka w świetle nowych źródet, „Komunikaty Mazursko-Warmińskie”, 2 (312), 2021, s. 209-222

Skolimowska A., Ioannes Dantiscus on the Way ad arcem Virtutis. Representations of the Coat of Arms as a Tool of Self-Creation of a Renaissance Humanist and Diplomat, w: Humanitas. Festskrift till Arne Jönsson, ed. A. M. H. Nilsson, A. Damtoft Poulsen, J. Svensson, Göteborg-Stockholm 2017, s. 440-463

Skolimowska A., Records of Friendship on the Threshold of a Diplomatic Career. Nardino Celinese's Propempticon \& Caspar Ursinus Velius' Genethliacon, Poems Dedicated to Ioannes Dantiscus, w: De amicitia. Transdisciplinary Studies in Friendship, ed. K. Marciniak, E. Olechowska, Warsaw 2016, s. 327-347

Urbański P., Between Ignatianism and Stoicism (Dantiscus, Sarbievius), $\mathrm{w}$ : Watki neostoickie $w$ literaturze polskiego renesansu $i$ baroku, ed. P. Urbański, Szczecin 1999, s. 173-189

Urbański P., Joannes Dantiscus and Italian Neo-Latin Poetry, w: Acta Conventus Neo-Latini Cantabrigiensis, ed. J.-L. Charlet, Tempe (AZ) 2003, s. $555-563$

Urbański P., Natura i taska w poezji polskiego baroku: okres potrydencki. Studia o tekstach, Kielce 1996

Urbański P., Theologia fabulosa. Commentationes Sarbievianae, Szczecin 2000 Wilkinson A. S., Iberian Books. Books Published in Spanish or Portuguese or on the Iberian Peninsula before 1601 / Libros ibéricos. Libros publicados en español o portugués o en la Peninsula Ibérica antes de 1601, Leiden-Boston 2010

\section{The Spanish Editions of Ioannes Dantiscus' Religious Hymns as a Tool of the Publisher's Self-Promotion}

In 1548 in Cracow, Ioannes Dantiscus (1485-1548), bishop of Ermland, and before that ambassador of Polish rulers to the court of Emperor Charles V, anonymously published a collection of religious hymns under the title Hymni aliquot ecclesiastici. Some twenty years after Dantiscus' death, this publication was reissued in Spain three times, together with the author's name. It was submitted for printing by the author's son-in-law, secretary to Emperor Charles V and Empress Isabella (later serving King of Spain Philip II), translator of Greek and Latin literature, Diego Gracián de Alderete. In 1538, he 
married Juana Dantisca, not quite twelve years old at the time, the daughter of the Polish diplomat and his Spanish mistress Isabella Delgada. Despite Dantiscus' disapproval, the marriage was a happy one. The couple had many children. One of their sons, Jeronimo Gracián Dantisco OCD (1545-1614), would later be the confessor of Saint Teresa of Ávila, and three - men of letters and clerks at the Spanish court: Antonio (1542-1576), Lucas (1543-1587), and Tomas (1558-1621). The Spanish editions of the hymns, even though the title pages do not indicate this, in fact, are not a reprint of the Cracow edition but a compilation of three prints: Dantiscus' Hymni aliquot ecclesiastici (1548), De nostrorum temporum calamitatibus (1530), and the Genethliacon for Dantiscus penned by Caspar Ursinus (1516, printed in 1522). Gracián uses them to build a monument to his father-in-law's great deeds and a testimony to his impeccable morals, supplementing the published texts with a panegyrical preface as well as making significant changes to the text of Ursinus' poem and introductory texts taken from the original editions - epigrams by Dantiscus and Petrus Royzius, and a letter from Stanislaus Hosius to Samuel Maciejowski. The paper describes these changes and their results.

Dr hab. Anna Skolimowska - filolog klasyczny, wydawca korespondencji średniowiecznej i renesansowej: Korespondencja żupnika krakowskiego Mikotaja Serafina z lat 1437-1459, Kraków 2006 (wyd. z W. Bukowskim, T. Płóciennikiem); seria Corpus Epistularum Ioannis Dantisci, http://al.uw.edu.pl/ serie-wydawnicze/corpus-epistularum-ioannis-dantisci/; internetowa publikacja Korpus Tekstów i Korespondencji Jana Dantyszka, dantiscus.al.uw.edu.pl. Wykładowca oraz kierownik Pracowni Edytorstwa Źródeł i Humanistyki Cyfrowej na Wydziale „Artes Liberales” Uniwersytetu Warszawskiego.

Anna Skolimowska - PhD with habilitation, Classical scholar, editor of medieval and Renaissance correspondence: Korespondencja żupnika krakowskiego Mikotaja Serafina z lat 1437-1459 [Correspondence of Cracow salt mine administrator Mikołaj Serafin], Kraków 2006 (with W. Bukowski, T. Płóciennik); the series Corpus Epistularum Ioannis Dantisci, http://al.uw. edu.pl/serie-wydawnicze/corpus-epistularum-ioannis-dantisci/; the internet publication Corpus of Ioannes Dantiscus' Texts \& Correspondence, http:// dantiscus.al.uw.edu.pl. Lecturer and head of the Laboratory for Source Editing and Digital Humanities of the Faculty "Artes Liberales", University of Warsaw.

E-mail: as@al.uw.edu.pl 